\title{
The Glycolytic Pathway is the Predominate Path for Glucose Utilization in Human Pancreatic Beta Cells (1.1B4)
}

\author{
Ahmed S. Hisab, M.Phil. \\ Jala A S Alahmed, PhD Student \\ Medical School, University of Nottingham, Nottingham, UK
}

Doi: 10.19044/esj.2018.v14n6p41 URL:http://dx.doi.org/10.19044/esj.2018.v14n6p41

\begin{abstract}
The oxidative metabolism of energy substrates has a paramount role in the stimulus secretion pathway of insulin. However, the role of glycolytic pathway in pancreatic beta cells is not very well understood. To address this, we have investigated and compared the functional effects of two mitochondrial substrates (glucose and $\alpha$-ketoisocaproate) between the human (1.1B4) and murine (MIN6) pancreatic beta cell lines. MTS assay was conducted as an indicator of the metabolic activity of both cell lines. Polarographic detection of $\left(\Delta \mathrm{O}_{2}\right)$ and lactate were used to measure the oxygen consumption rate and anaerobic glycolysis respectively. The mitochondrial redox state was monitored via RH123 distribution and $\mathrm{NAD}(\mathrm{P}) \mathrm{H}$ autofluorescence. The metabolic assays showed glucose stimulated MTS reduction in MIN6 cells in a time and concentration dependent manner and nor in 1.1B4. Both sub strates failed to affect OCR, NADPH and increased lactate production in 1.1B4 cells. However, they stimulated OCR, increased $\mathrm{NADPH}$, increased lactate output but was less extent and hyperpolarized the mitochondria in MIN6 cells. The above results showed that 1.1B4 cells are mainly depending on the glycolytic pathway different from MIN6 cells which rely on mitochondrial respiration. In conclusion, 1.1B4 cell line represents a new model to study the bioenergetics profile because it depends on the anaerobic glycolysis rather than aerobic respiration of the other models such as MIN6 and islets.
\end{abstract}

Keywords: Oxidative metabolism, glycolysis, mitochondria, insulin secretion, pancreatic $\beta$-cell

\section{Introduction}

Glycolysis is the process by which one mole of glucose breaks down to produce two moles of pyruvate and to provide energy as ATP. Glucose 
enters beta cells via two types of glucose transporters such as glut-2 and glut -1by facilitated diffusion process. It is phosphorylated to glucose -6phosphate by glucokinase enzyme (GK). This enzyme has high affinity to glucose $(\mathrm{Km}$ of $=5 \mathrm{mM})$ which explains the concentration dependence of the beta cell response to glucose in the physiological range (Meglasson and Matschinsky, 1984, 1986; Matschinsky et al., 1993; Aguilar-Bryan and Bryan, 1999). In the lack of oxygen, pyruvate produces lactate by anaerobic glycolysis (Barrett et al., 2012). However, in cancer cells and some cell lines lactate can be produced in the presence of sufficient amount of oxygen according to Warburg effect (WARBURG, 1956). In the presence of oxygen pyruvate enters the mitochondria and metabolizes in tricarboxylic acid cycle (TCA) to generate 38 molecules of adenosine triphosphate (ATP).

The mitochondrion consists of matrix surrounded by two membranes inner and outer with intermembrane space in between them. TCA cycle happens in the matrix while oxidative phosphorylation occurs in the inner membrane. In the oxidative phosphorylation process, electrons are transferred from electron donors (NADH and $\mathrm{FADH}_{2}$ ) produced from TCA cycle to electron acceptors (oxygen) in redox reactions. The redox reactions achieved by several steps called electron transport chain via five protein complexes (I$\mathrm{V})$. The process commences when the electron donors are donate two electrons during the reacting with NADH dehydrogenase enzyme, which is also called complex I. As a result of passing of those electrons through complex I, four protons $\left(\mathrm{H}^{+}\right)$will be transported from matrix to intermembrane space. Moreover, coenzyme Q10 or ubiquinone (Q) will be reduced to ubiquinol $\left(\mathrm{QH}_{2}\right)$ (Hirst, 2010). Second step in electron transport chain is the effect of complex-II which is also known as succinate dehydrogenase enzyme. It oxidizes succinate to fumarate and transports the electrons via reduction of flavin adenine dinucleotide (FAD) which leads to reduce ubiquinone as well. The oxidation of succinate in complex II produces less energy than that of NADH in complex I. Therefore, complex II does not transport $\left(\mathrm{H}^{+}\right)$throughout the membrane and it is considered the only complex that transport electrons without pumping $\left(\mathrm{H}^{+}\right)$to the intermembrane space. Complex III (cytochrome c reductase) consists of two protein subunits or dimer. In each subunit, it oxidises the ubiquinone to ubiquinol, releasing two $\left(\mathrm{H}^{+}\right)$to the intermembrane space and the electrons are passed through the cytochrome units of the complex (Chaban et al., 2014).

The final enzyme of the mitochondrial electron transport chain is cytochrome c oxidase or complex IV which receives electrons from complex III. Two water molecules will be generated from the reaction of the elections with the final acceptor (oxygen). During this process, four $\left(\mathrm{H}^{+}\right)$are pumped to the intermembrane space (Calhoun et al., 1994; Chaban et al., 2014). As each complex moves electrons along the chain, protons are pumped out of the 
matrix into the intermembrane space. The proton gradient generated is used to drive ATP synthesis by Complex $\mathrm{V}\left(\mathrm{F}_{1} \mathrm{~F}_{0}\right.$ ATP synthase), which phosphorylates ADP to ATP (Kim et al., 2008). This proton gradient may commonly refer to as the mitochondrial membrane potential $(\sim 150-180 \mathrm{mV})$ which is significantly higher than the plasma membrane potential; (Valdez et al., 2006) vs.( 60-90mV (Wright, 2004).

The widely accepted key process of glucose stimulated insulin secretion is ATP-sensitive $\mathrm{K}^{+}$channels $\left(\mathrm{K}^{+}\right.$-АTP) dependent. The increase of ATP/ADP ratio causes closure of the $\mathrm{K}^{+}$-ATP sensitive channels is leading to a depolarization of cell membrane and opening the voltage gated calcium channel (Aguilar-Bryan and Bryan, 1999). This will increase the cytosolic $\mathrm{Ca}^{2+}$ levels which is directly promoting exocytosis of insulin.

The aim of this study is to compare metabolic profiles of two different pancreatic beta cell lines, (1.1B4) human derived cell line vs murine (MIN6). The rational is to find out which cell line is more relevant for the study of the pancreatic beta cells bioenergetics.

\section{Methodology \\ Cell lines}

Two cell lines had been used in this study. Firstly, 1.1B4 (ECACC87092802) a cell line designed by the electrofusion of a primary culture of human pancreatic islets with PANC-1, a human pancreatic ductal carcinoma cell line (Lieber et al., 1975; McCluskey et al., 2011). 1.1B4 cells are considered to be a good model for secreting pure insulin (McCluskey et al., 2011). Cells maintained with RPMI 1640 which supplemented by $10 \%(\mathrm{v} / \mathrm{v})$ foetal calf serum (FCS) in addition to $+1 \%(\mathrm{w} / \mathrm{v})$ Penicillin $1000 \mathrm{unit} / \mathrm{ml}$ and streptomycin $0.1 \mathrm{mg} / \mathrm{ml}$. Passage numbers $32-40$ were used.

The MIN6 cell line is a transgenic mouse insulinoma cells established by Miyazaki in 1990. We have chosen Min6 because it is homogenous and response to glucose with the physiological range in addition to it expresses glucose transporter and glucose which make Min6 ideal for this study (Ishihara et al., 1993). Although MIN6 have been reported to contain and secrete other pancreatic endocrine hormones, these cells still remain primarily b-cell in function (Nakashima et al., 2009). Cell were cultured in RPMI 1640, supplemented by $10 \%(\mathrm{v} / \mathrm{v})$ foetal calf serum (FCS). Passages numbers 19-40 were used.

\section{MTS Assay}

The water-soluble salt MTS (3-[4, 5dimethylthiazol-2-yl] -5-[3carboxymethoxy-phenyl] -2-[4-sulfophenyl] -2H-tetrazolium) assay depends on reduction of the MTS substrate to produce coloured formazan. This assay does not need to solubilize the cells by using acidified isopropanol, which may 
disrupt the cells integrity. MTS receives electrons via an intermediate electron acceptor Phenazine methosulfate (PMS) which amplifies (fluorescence signal at $490 \mathrm{nM}$ (Cory et al., 1991; Janjic and Wollheim, 1992; Segu et al., 1998). The MTS assay was performed according to the manufacturer's instructions (Celltiter 96 aqueous nonradioactive cell- proliferation assay, Promega, Madison, WI). The absorbance was measured at $490 \mathrm{~nm}$ by plate reader. Readings were corrected for the background by subtracting the blank (MTS/PMS regent in Hanks without the cells) from the readings. Three experiments have been performed with triplicate wells in each experiment.

\section{Oxygen Consumption Rate (OCR)}

Mitochondrial respiratory rate of 1.1B4 and MIN6 cell suspensions were measured polarographically using Clark Oxygen. The partial pressure of $\mathrm{O}_{2}$ $\left(\mathrm{PO}_{2}\right)$ was measured at a polarographic voltage of $0.6 \mathrm{~V}$ with electrodes previously calibrated at $100 \%$ air saturation (vigorous gassing with air, $0.25 \mathrm{mM}$ ) and $0 \%$ (addition of $\mathrm{Na}_{2} \mathrm{~S}_{2} \mathrm{O}_{4}$ ) (Daunt et al., 2006). The background of Oxygen consumption by electrode was determined by the addition of $6 \mathrm{mM}$ sodium azide to block oxidative respiration at cytochrome $\mathrm{C}$.

\section{Lactate production}

The rate of lactate production of both1.1B4 and MIN6 was measured polarographically with sarissa lactate enzyme electrodes (Sarissa Biomedical Ltd Coventry, UK) as previously mentioned by Brown et al., 2012. $4 \mathrm{~mL}$ of cell suspension were loaded in to a chamber, where the potential of the lactate electrode was set at $500 \mathrm{mV}$ relative to $\mathrm{Ag} / \mathrm{AgCl}$ reference electrode. Electrical current will be generated due to the oxidation of lactate by the lactate oxidase enzyme on the surface of a carbon fiber electrode. This current is a stoichiometric measure of lactate concentration. The lactate output rate was calculated according to the following equation:

ESubstrate $($ nmol 107 cell-1 min-1) $=($ substrate $) * 60 /($ cells count $) /$ calibration value

\section{Mitochondrial membrane potential}

Rhodamine123 (Rh123) was used to monitor the mitochondrial membrane potential, $\Delta \Psi \mathrm{m}$, with methods similar to those described previously with some modifications (Duchen et al., 1993). The dye was excited at 480 $\mathrm{nm}$ and the emitted fluorescence monitored at $530 \mathrm{~nm}$. Cells were plated on $22 \mathrm{~mm}$ cover-slips and incubated with $10 \mu \mathrm{g} / \mathrm{ml} \mathrm{rh} 123$ for $10 \mathrm{~min}$ at room temprature. Images were captured at a frequency of $1 \mathrm{~Hz}$ with a Photonics ISIS CCD camera, DT3155 frame grabber (Data translation, UK) and Imaging workbench software (IW5.2 INDEC BioSystems, Santa Clara, CA, USA). Only single and clusters of cells that responded to glucose were chosen for 
further analysis using Origin software with bespoke scripts written in Labtalk (OriginLab Corporation, MA USA). Images were background corrected and the average fluorescence intensity for each field of cells calculated.

\section{NAD(P)H measurements}

$\mathrm{NAD}(\mathrm{P}) \mathrm{H}$ experiments were carried out using epifluorescence microscope as previously described (e.g. Duchen, 1992a,b; Duchen and Biscoe, 1992a,b). NAD(P)H produced from glucose and/or amino acid metabolism in the mitochondria . Cells were excited by light at $350 \mathrm{~nm}$ and measured with a bandpass fliter combination between 400 and $500 \mathrm{~nm}$. To normalize the $\mathrm{NAD}(\mathrm{P}) \mathrm{H}$ response experiments, $10 \mathrm{mM}$ glucose was used to reach a maximal response and this was set as a $100 \%$.

\section{Dose-response relationships glucose and KIC:}

The dose-response relationships were quantified by best fits of the data with the following equation using prism via best fit non-linear regression:

$$
Y=\frac{Y_{\text {MAX }}-Y_{\text {MIN }}}{1+\left(E C_{50} / G\right)^{h}}+Y_{M I N}
$$

Where $\mathrm{G}$ is the concentration of substrates, $\mathrm{EC}_{50}$ is the concentration that produces the half-maximal response, $\mathrm{Y}$ is the response magnitude, $\mathrm{Y}_{\mathrm{MAX}}$ is the maximal response, $\mathrm{Y}_{\mathrm{MIN}}$ is the minimal response, and $\mathrm{h}$ is an index of slope. Fits were performed in PRISM 6 (GraphPad Software Inc., San Deigo, CA).

\section{Statistical analysis}

Data are expressed as mean \pm S.E.M. Parametric statistical analysis was used when the data are normally distributed (D' Agostino Pearson ominubus normality test). All statistical analysis had been done Prism (6.0, GraphPad software, San Diego California, USA). EC 50 and h values are quoted with $95 \%$ confidence intervals. Statistical significant was accepted at $P<0.05$.

\section{Results}

\section{MTS}

In 1.1B4 cells, there was a slight increase in MTS reduction after adding of $1 \mathrm{mM}$ glucose, which saturated at $10 \mathrm{mM}$. The $\mathrm{EC}_{50}$ of glucose stimulated MTS reduction was $1.6 \mathrm{mM}(0.4$ to $695 \% \mathrm{CI})$ within an h (slope of index) of 1 (Fig. 1). In MIN6 cells, the basal MTS signal was lesser than in 1.1B4 cells. There was a progressive increase in MTS reduction with 
increasing glucose concentration at $0.01 \mathrm{mM}$ glucose, which saturated at $10 \mathrm{mM}$ as well. The $\mathrm{EC}_{50}$ of glucose stimulated MTS reduction in MIN6 was $1.8 \mu \mathrm{M}$ (2 to $3095 \% \mathrm{CI}$ ) and h of 1 (Fig. 1)

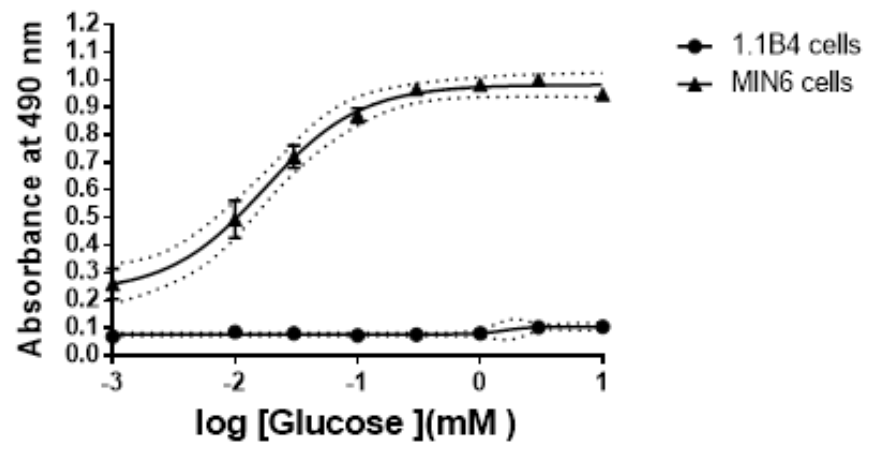

Fig. 1: Glucose concentration-response relationship for the reduction of MTS in 1.1B4 and MIN6 cells. Solid lines are best fits of equation 1 with the parameters given in text. Dots line are confidence interval Cells were incubated for $60 \mathrm{~min}$. Data are mean $\pm \mathrm{SEM}$. $\mathrm{N}=6$.

\section{Oxygen consumption rate}

In this study, we were conducted the OCR experiments as an indicator to assess the mitochondrial activity of 1.1B4 and MIN6 cell lines. In the absence of added substrate, 1.1.B4 cells possessed a linear basal respiratory rate at $-27 \mathrm{nmoles} 10^{7}$ cells $^{-1} \mathrm{~min}^{-1}$ (Fig. 2A). Adding $10 \mathrm{mM}$ glucose inhibited the OCR by $\sim 24 \pm 4.6 \%$ ( $\mathrm{P}<0.001$, Wilcoxon matched-pairs signed rank test)(Fig. 2A). The basal OCR of MIN6 cell was -23 nmoles $10^{7}$ cells $^{-1} \mathrm{~min}^{-1}$, and within 1 min of adding $10 \mathrm{mM}$ glucose the OCR increased by $\sim 25 \pm 4.5 \%$ $(\mathrm{P}<0.001$, Wilcoxon matched-pairs signed rank test) (Fig. 2B).

A)

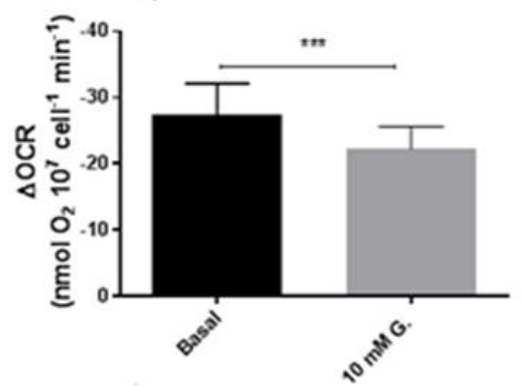

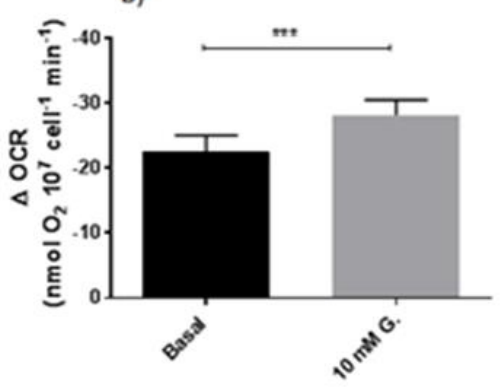

Fig. 2: The effect of glucose $10 \mathrm{mM}$ on Oxygen consumption rate $(\mathrm{OCR})$ in 1.1B4 (A)

MIN6 cells (B). Glucose inhibits oxygen consumption 1.1B4 (A) and stimulated it in MIN6 cells (B) compared to those measured in the absence of exogenous substrate (basal). Data are mean \pm SEM. Statistical significance determined by paired $T$ test. $N=15$. 

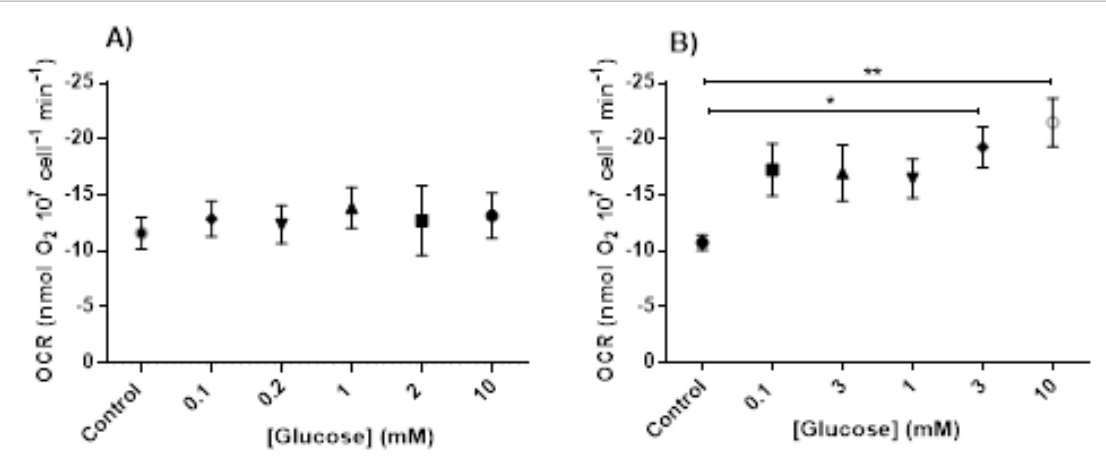

Fig. 3: Relationship between glucose concentration and $\mathrm{O}_{2}$ consumption in $1.1 \mathrm{~B} 4$ cells $(\mathrm{A})$ and MIN6 cells (B). Data are mean \pm SEM. $\mathrm{N}=18$.

Different concentrations of glucose had been failed to change the OCR in comparison to the control $\left(\mathrm{H}_{2} \mathrm{O}\right)$ in $1.1 \mathrm{~B} 4$ cells (as shown in figure $3 \mathrm{~A}$ ). While in MIN6 cells, glucose Stimulated OCR in a concentration-dependent manner which started from $3 \mathrm{mM}$ in comparison with vehicle control $\left(\mathrm{H}_{2} \mathrm{O}\right)$ $(\mathrm{P}<0.05$, Dunnett's multiple comparisons test). Further increased in OCR had been achieved by $10 \mathrm{mM}$ glucose stimulated OCR $(\mathrm{P}<0.01$, Dunnett's multiple comparisons test) (Fig 3B). Since glucose did not affect the OCR in 1.1B4 cells and it did in MIN6, this suggests that there are differences in the mitochondrial function between 1.1B4 and MIN6. Thus, we used $\alpha$ ketoisocaproate (a fuel that feeds directly into the mitochondrial tricarboxylic acid cycle (Duchen et al., 1993; Gao et al., 2003; Daunt et al., 2006). We found that $\alpha$-ketoisocaproate failed to stimulate OCR compared to the Vehicle control $\left(\mathrm{H}_{2} \mathrm{O}\right)$ in 1.1B4 cells (Fig. 4.A). However, in MIN6 cells, $\alpha$ ketoisocaproate increased OCR in a concentration-dependent manner in comparison with Control $\left(\mathrm{H}_{2} \mathrm{O}\right)$. $(\mathrm{P}<0.01$, Dunnett's multiple comparisons test)(Fig. 4B).
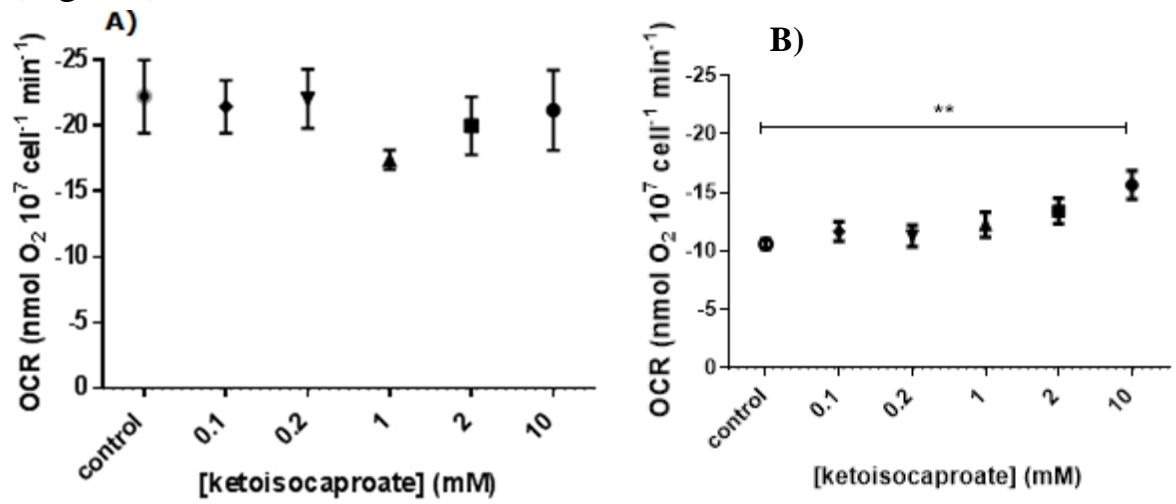

Fig. 4: Relationship between $\alpha$-ketoisocaproate concentration and $\mathrm{O}_{2}$ consumption in1.1B4 cells (A) and MIN6 cells (B). Data are mean \pm SEM. $N=8$. 


\section{Lactate production}

In order to compare the rate of glycolysis of 1.1B4 and MIN6 cells, we measured the lactate production as an indicator of conversion of pyruvate in to lactate. In the absence of exogenous metabolic substrate, 1.1B4 cells possessed a linear basal lactate production at 2 nmoles $10^{7}$ cells $^{-1} \mathrm{~min}^{-1}$ (Fig. 5A). Adding $10 \mathrm{mM}$ glucose significantly increased lactate production by $\sim 93$ $\pm 9.5 \%$ ( $\mathrm{P}<0.001$, Wilcoxon matched-pairs signed rank test) compared to the basal (Fig. 5A). The basal rate of lactate production of MIN6 cells was at -10 \pm 2.4 nmoles $10^{7}$ cells $^{-1} \mathrm{~min}^{-1}$. Within $1 \mathrm{~min}$ of adding $10 \mathrm{mM}$ glucose, lactate production significantly increased by $\sim 25 \pm 4.5 \%(\mathrm{P}<0.001$, Wilcoxon matched-pairs signed rank test) (Fig. 5B).

A)

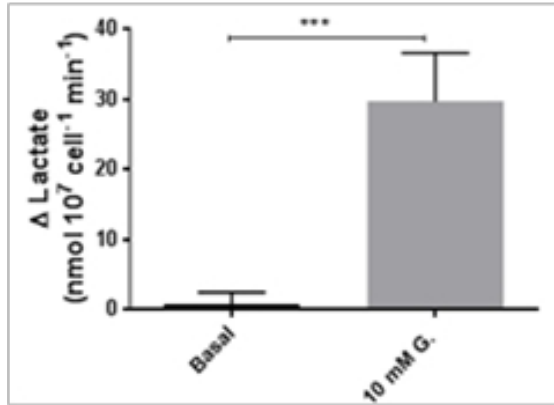

B)

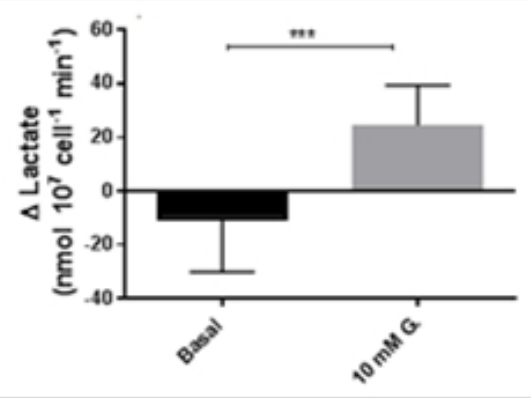

Fig. 5: The effect of glucose $10 \mathrm{mM}$ on lactate production rate in 1.1B4 (A) MIN6 cells

(B). 10mM glucose (G.) significantly increased lactate output in both 1.1B4 (A) and MIN6

(B). Data are mean \pm SEM. Statistical significance determined by paired $T$ test. $\mathrm{N}=15$.

\section{The effect of glucose and $\alpha$-ketoisocaproate (KIC) on the mitochondrial membrane potential}

In addition to OCR, we investigated the mitochondrial redox by monitoring mitochondrial membrane potential $\Delta \psi \mathrm{m}$ using Rh123 fluorescence in MIN6 cells. In the absence of exogenous metabolic substrate, $\Delta \psi \mathrm{m}$ was static in both glucose and KIC experiments (Fig. 6B\&D). After 1 min of adding $10 \mathrm{mM}$ glucose, it produced significant decrease in Rh123 fluorescence $\sim 28 \pm 1.25 \%$ ( $\mathrm{P}<0.0001$, paired t test) (Fig. 6A). Similar result had obtained by adding $10 \mathrm{mM}$ KIC which decreased the Rh123 fluorescence by $\sim 20 \pm 1.25 \%$ ( $P<0.0001$, paired t test) as shown in (Fig. C\&D). Addition of $1 \mu \mathrm{M}$ FCCP, a mitochondrial uncoupler which collapses of $\Delta \Psi \mathrm{m}$ (Duchen et al., 1993; Daunt et al., 2006) as shown in (Fig. 6B\&D). 

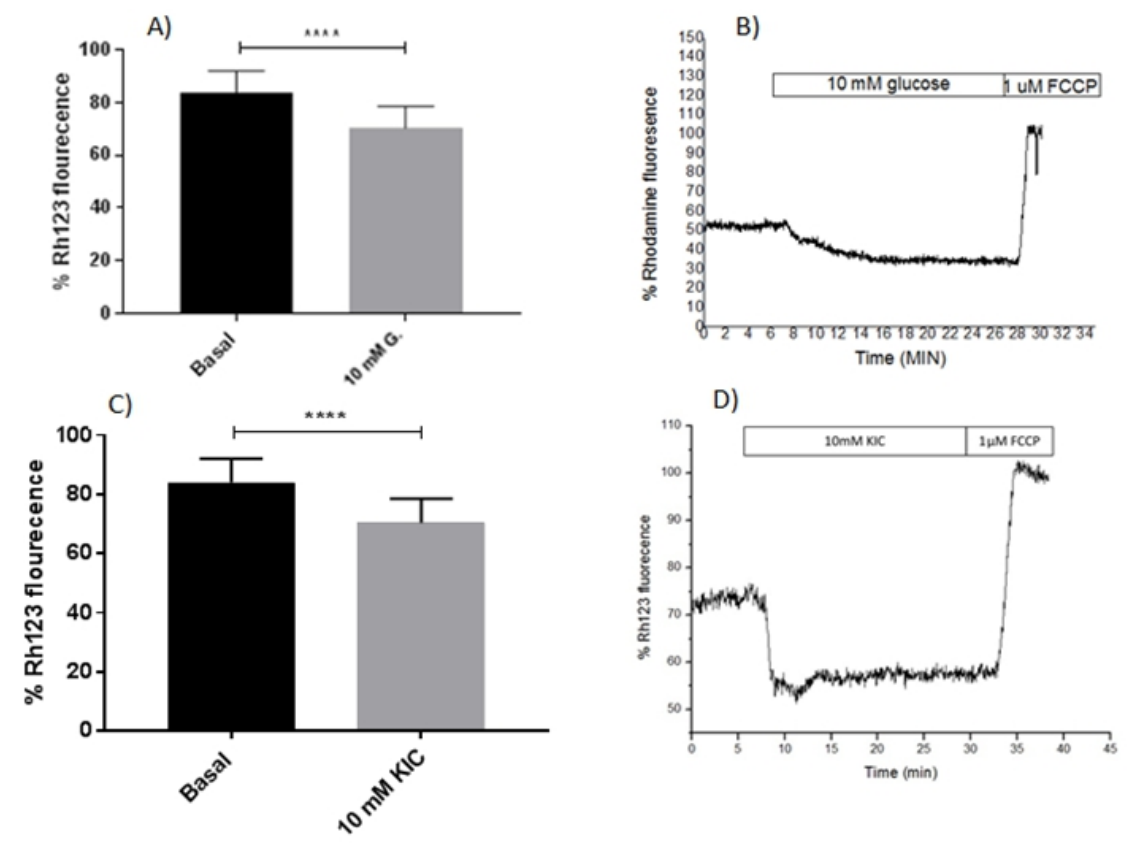

Fig. 6: Rh123 fluorescence as a measure of the mitochondrial membrane potential, $\Delta \Psi$ mit. Effects of $10 \mathrm{mM}$ glucose (G.)(A) and KIC (C) as indicated on $\Delta \Psi$ mit, in MIN6 cells. E,D $\Delta \Psi$ mit is represented by the change in $\mathrm{Rh}-123$ fluorescence relative to that measured in the absence of the sugar(100\%). Records are representative of at least 3 different experiments for each condition and are formed from the average of at least 7 ROIs. Data are the means SD. Data is from at least 5 independent preparations in each case, where $\mathrm{n}$ is the total number of ROI measured for each condition.

\section{Changes in 1.1B4 NAD(P)H autofluorescence in comparison to MIN6 cells in response to $10 \mathrm{mM}$ glucose and $\alpha$-ketoisocaproate (KIC).}

The increase in the substrate level leads to the increment in the $\mathrm{NAD}(\mathrm{P}) \mathrm{H}$ and subsequently tricarboxylic acid cycle (TCA)(Duchen et al., 1993). The aim of this experiment is to support that the glucose stimulated OCR in MIN6 cells and it did not in 1.1B4 cells which may be due to abnormal mitochondrial oxidation. We therefore, measured autofluorescence under conditions that evoke fluorescence of NAD (P) H. Fig. 7A\&B showed that the effect of $10 \mathrm{mM}$ glucose and on the NAD (P) H signal of a single 1.1B4. Treating of 1.1B4 cells to glucose had no effect on the $\mathrm{NAD}(\mathrm{P}) \mathrm{H}$ levels compared to the basal (Fig. 7A\&B). Subsequent addition of $1 \mu \mathrm{M}$ rotenone (complex I inhibitor of electron transport chain) failed to affect $\mathrm{NAD}(\mathrm{P}) \mathrm{H}$ signals in the presence of glucose (Fig. 7A\&B). However, exposure of MIN6 cells to $10 \mathrm{mM}$ glucose increased NADPH levels by $\sim 10 \pm 0.9 \%$ ( $\mathrm{P}<0.01$, Sidak's multiple comparisons test) after a delay of one minute compared to the basal (Fig. 7C\&D). $1 \mu \mathrm{M}$ rotenone further elevated NAD(P)H signals by $\sim 15$ $\pm 1.9 \%$ ( $\mathrm{P}<0.001$, Sidak's multiple comparisons test) in response to glucose (Fig. 7C\&D). However, the same challeng of $10 \mathrm{mM}$ KIC mitochondrial 
substrates (Duchen et al., 1993; Gao et al., 2003; Daunt et al., 2006) did not affect NAD $(\mathrm{P}) \mathrm{H}$ levels compared to the basal in 1.1B4 cells (Fig. 7E\&F). Also, addition of $1 \mu \mathrm{M}$ rotenone (complex I inhibitor of electron transport chain) failed to affect $\mathrm{NAD}(\mathrm{P}) \mathrm{H}$ signals in the presence of KIC (Fig.7E\&F). while in MIN6 cells , $10 \mathrm{mM}$ KIC caused as increase in the NAD(P)H signals by $\sim 5 \pm 0.5 \%$ ( $\mathrm{P}<0.01$, Sidak's multiple comparisons test)(Fig.7G\&H). After one minute delay of $1 \mu \mathrm{M}$ rotenone further increased NADPH levels by $15 \pm$ $1.9 \%$ ( $\mathrm{P}<0.0001$, Sidak's multiple comparisons test) in response to KIC (Fig. $7 \mathrm{G} \& \mathrm{H})$.
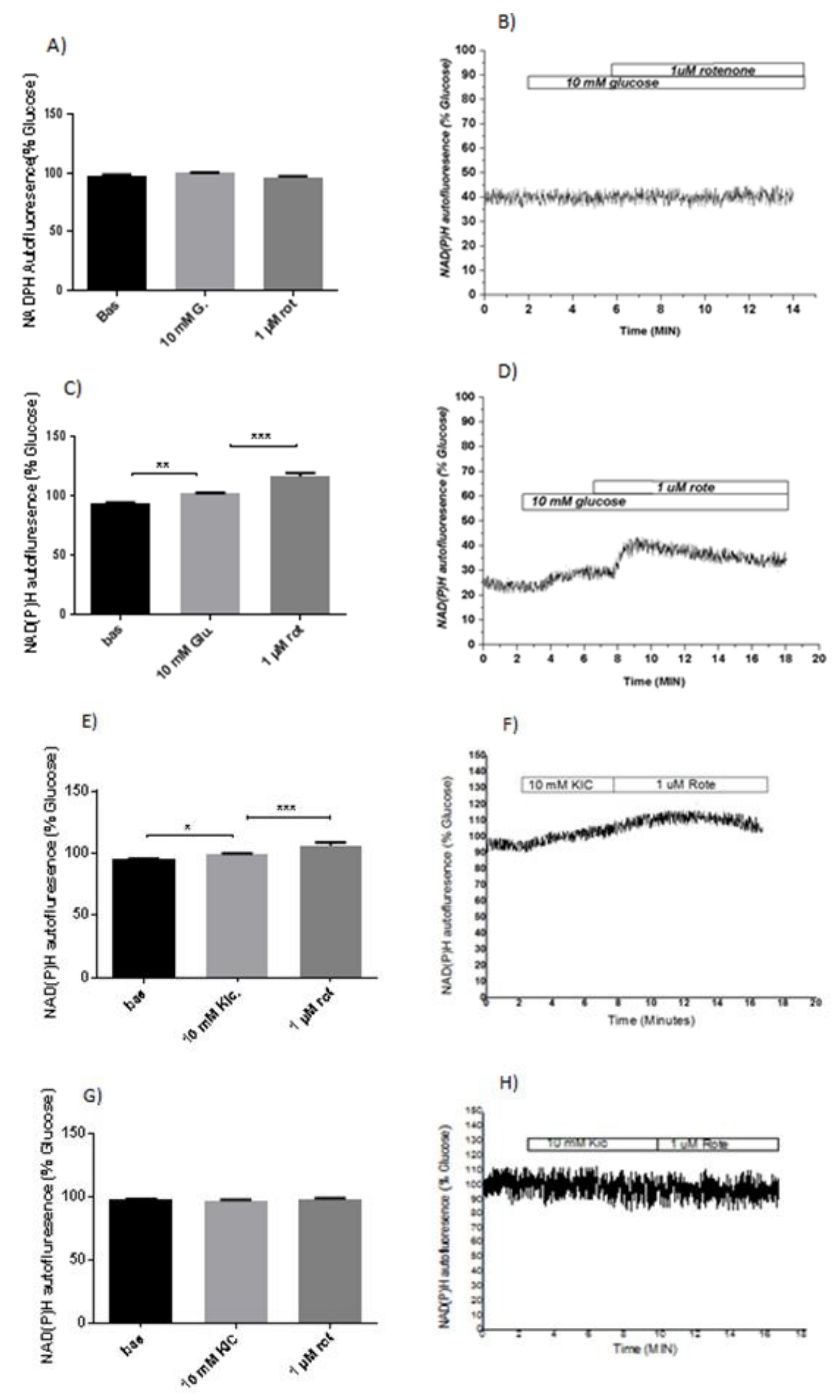

Fig. 7: Effect of $10 \mathrm{mM}$ glucose $(\mathrm{A}, \mathrm{B})$ and $\mathrm{KIC}(\mathrm{G}, \mathrm{H})$ on the $\mathrm{NAD}(\mathrm{P}) \mathrm{H}$ levels in the 1.1B4. $10 \mathrm{mM}$ glucose (C,D) and KIC (E,F) on the NAD(P)H levels MIN6 cells. $\mathrm{N}=101$ 130 cells collected from 4-16 experiments where the minimum number of cells is 7 in each 


\section{Discussion}

MTS

Since oxidative respiration of $\beta$-cells are generally linked with the uptake and metabolism of glucose and other fuels, therefore assessments of the metabolic activity of 1.1B4 and MIN6 cells are important. As a result, during static incubations of these cells with glucose may increase the signal derived via the reduction of MTS in a time- and dose-dependent manner. The key rate-limiting step for glucose metabolism is its phosphorylation to glucose-6-phosphate, where the subsequent stimulus-secretion cascade leads to insulin release in pancreatic $\beta$-cells (Matschinsky et al., 1993; Sakura et al., 1998). Low affinity glucokinase is predominantly responsible for phosphorylation in native beta cells during the stimulus-secretion pathway, possess $\mathrm{EC}_{50}$ values for glucose around 5-10 mM (Sakura et al., 1998; Martín et al., 1999). The micromollar $\mathrm{EC}_{50 \text { s }}$ values found for glucose phosphorylation within the stimulus-secretion pathway suggest that high-affinity hexokinase activity $(\mathrm{Km} \sim 300 \mu \mathrm{M})$ predominate in MIN6 (Ishihara et al., 1993) over that of glucokinase in 1.1B4 cells (McCluskey et al., 2011). In this study we found that the $\mathrm{EC}_{50}$ for glucose-stimulated MTS reduction of $1.1 \mathrm{~B} 4$ was $1.6 \mathrm{mM}$ compared to $1.8 \mu \mathrm{M}$ of MIN6. Although, these cell lines produce the hexokinase to metabolize glucose (Ishihara et al., 1993), the variation in $\mathrm{EC}_{50}$ of MTS reduction could be due to high levels of glucokinase in 1.1B4 (McCluskey et al., 2011) in comparison to MIN6 which mainly depends on hexokinase I (Ishihara et al., 1993). The same principle would be suggested to explain the differences between highly content glucokinase mouse islet $\mathrm{EC}_{50}$ $=8 \mathrm{mM}$ (Panten and Klein, 1982) in one hand and murine cell line MIN6 on the other hand. Since both of 1.1B4 and beta cells from pancreatic islet depend on glucokinase activity, therefore 1.1B4 had a comparable $\mathrm{EC}_{50}$ of MTS reduction with human pancreatic islets $\left(\mathrm{EC}_{50}=12 \mathrm{mM}\right)$ found by Panten and Klein (1982) and Soria et al. (2010).

\section{Oxygen consumption rate}

Since we interested in the bioenergetics of the pancreatic beta cell; we then investigated aerobic respiration of 1.1B4 cells and MIN6 cells. In 1.1 B4 and MIN6 cells, basal $\mathrm{O}_{2}$ consumption showed a linear pattern which varied between experiments. Figure $2 \mathrm{~A}$ showed that basal OCR at $27-$ nmoles $10^{7}$ cells ${ }^{-1} \mathrm{~min}^{-1}$ of $1.1 \mathrm{~B} 4$ cells. However, the basal OCR at 23 nmoles $10^{7}$ cells $^{-1}$ min $^{-1}$ of MIN6 cells. Earlier studies confirm that basal levels of Oxygen consumption rate were roughly $20 \mathrm{nmol} 10^{7}$ cells $^{-1} \mathrm{~min}^{-1}$ in MIN6 cell lines (Daunt et al., 2006). Difference in the basal respiration may be due to the presence of fatty acids in the cells suspensions, which metabolised by mitochondria and increase reducing equivalents leading to an increase oxidative respiration (Lopaschuk et al., 2010). The 1-fold inhibition in the rate 
of $(\Delta \mathrm{O} 2)$ produced by $10 \mathrm{mM}$ glucose. This suggests the adding of glucose was either metabolized solely by glycolysis and apparently not by the TCA or the cells have marginal oxidative capacity (Warburg 1956). This idea may support these findings by supplementary data stated that glucose utilization (glycolysis) occurs at a much higher rate than glucose oxidation in 1.1B4 cells (McCluskey et al., 2011) and in human islets (Doliba et al., 2012). This may lead to inhibit of oxidative respiration by glycolytic products Crabtree effect (Diaz-Ruiz et al., 2011). The 2-fold stimulation in the rate of oxygen consumption produced by $10 \mathrm{mM}$ glucose MIN6 cells; an observation is comparable with previous findings, which recorded that $20 \mathrm{mM}$ glucose caused an $80 \%$ increase, approximately $10 \mathrm{nmol} \mathrm{O}_{2} 10^{7} \mathrm{cell}^{-1} \mathrm{Min}^{-1}$ in MIN6 cells $\mathrm{O}_{2}$ consumption (Daunt et al., 2006), 5-10 nmol O $210^{7}$ cell $^{-1} \mathrm{Min}^{-1}$ in rat islets (Hutton and Malaisse, 1980) and $40 \mathrm{nmol} \mathrm{O}_{2} 10^{7} \mathrm{cell}^{-1} \mathrm{~min}^{-1}$ in mouse islets (Daunt et al., 2006). The above data provide strong evidence that the principle fate of glucose in MIN6 cells, which are enzymatically similar to $\beta$ cells, is mitochondrial oxidation.

\section{Effect of glucose and $\alpha$-ketoisocaproate on the OCR}

The present study showed that glucose and $\alpha$-ketoisocaproate failed to affect OCR compared to the control $\left(\mathrm{H}_{2} \mathrm{O}\right)$ in $1.1 \mathrm{~B} 4$ cells. This suggests that glucose completely metabolized by glycolysis not by TCA cycle (WARBURG, 1956). Another factor of consideration is that the problem may associate with the cell culture which results from disruption of cell-to-cell interaction. This may influence cellular functions in the organism by stillunknown mechanisms. Additionally, genetic influence of the cells might add additional complications and can eventually modify some native functions and responses of the cell, which is possibly in most pancreatic beta cell lines have defective secretory characteristics and are unable to respond to glucose in the physiological range (Skelin et al., 2010). Another reason why $1.1 \mathrm{~b} 4$ cells had a poor response to glucose is the decrease with passage number (McCluskey et al., 2011). These findings consistent with poor mitochondrial function of $1.1 \mathrm{~B} 4$ cells. However, in MIN6 cells glucose and $\alpha$-ketoisocaproate stimulated OCR; an idea supported here in MIN6 by the ability of this substrate to stimulate oxidative respiration (Hutton and Malaisse, 1980; Panten and Klein, 1982; Daunt et al., 2006).

\section{Lactate production}

Further to OCR, we estimated lactate production in both $1.1 \mathrm{~B} 4$ and MIN6 cells. Figure 2B showed basal lactate production at 3 nmoles $10^{7}$ cells ${ }^{1} \mathrm{~min}^{-1}$ of $1.1 \mathrm{~B} 4$ cells. $1.1 \mathrm{~B} 4$ cells accompanied by 9 -fold stimulation in the lactate production 1.1B4 cells which leads to an increase lactate production (WARBURG, 1956; Sener and Malaisse, 1976). No previous data had been 
reported for lactate output in human pancreatic beta cells. However, a study by (MacDonald and Fahien, (1990) stated that glycolytically, rather than mitochondrially, generated ATP might be crucial for closure of $\mathrm{K}^{+}$-ATP channels, which in turn may regulate insulin secretion in rat $\beta$ cells. Conversely, it has been shown that high mitochondrial glycerol phosphate dehydrogenase activity with low lactate dehydrogenase (LDH) activity may allow glycolytic pyruvate to enter into mitochondrial oxidation in rat $\beta$-cells (Sek-ine et al., 1994). In terms of lactate output in MIN6 cells, glucose stimulated lactate production compared to the basal. This can be accounted for by the increase in $[\mathrm{NADH}]_{\mathrm{d}} /\left[\mathrm{NAD}^{+}\right]_{\mathrm{c}}$. These results consistent with that published by (Sener and Malaisse, 1976) stated that high rates of glucoseinduced lactate output from rat isolated islets.

\section{Effect of glucose and KIC on mitochondrial membrane potential ( $\Delta \psi \mathrm{m})$}

Since glucose and KIC stimulated oxidative respiration, we found that they produced an drop in Rh123 fluorescence compared to the basal; an effect consistent with the polarization of $\Delta \psi \mathrm{m}$ that occurs with stimulation of mitochondrial electron transport on oxidative respiration of sugar (Duchen et al., 1993) and KIC which is a fuel that feeds directly into the mitochondrial tricarboxylic acid cycle (Duchen et al., 1993; Gao et al., 2003; Daunt et al., 2006). Addition of FCCP evoked a rapid increase in fluorescence; an effect consistent with rapid and total collapse of $\Delta \psi \mathrm{m}$ caused by the mitochondrial protonphore (Duchen et al., 1993). In other experiments, after energization of $\Delta \psi \mathrm{m}$ with $10 \mathrm{mM}$ glucose, the addition of rotenone produced an immediate increase in Rh123 fluorescence. These results suggested that MIN6 cells depend on mitochondrial respiration. However, 1.1B4 cells mitochondrial membrane potential, it was difficult to measure because the cells did not take the $123 \mathrm{RH}$ for unknown reason.

\section{NAD(P)H autofluorescence}

The measurement of the endogenous fluorescent compound NAD(P)H serves as an indicator of glucose-induced changes of the beta cell energy metabolism (Panten et al., 1973; Duchen et al., 1993; Martens et al., 2005; Ghaly et al., 2014). As NAD(P)H autofluoresence is resulting mainly from the mitochondria (Pralong et al., 1990; Patterson et al., 2000; Luciani et al., 2006; De Marchi et al., 2014; Ghaly et al., 2014). Therefore, an increase in the fluorescence signals an increase in the reduced state of the pyridine nucleotide $\mathrm{NAD}(\mathrm{P}) \mathrm{H}$. Thus, Increased activity of the tricarboxylic acid cycle in response to increased substrate supply leads to an increase in the $\mathrm{NAD}(\mathrm{P}) \mathrm{H}$ (Duchen et al., 1993), in 1.1B4 cells, the results denote that both $10 \mathrm{mM}$ glucose and KIC which is considered to be a mitochondrial fuel (Duchen et al., 1993; Gao et al., 2003; Daunt et al., 2006) had no effect on $\mathrm{NAD}(\mathrm{P}) \mathrm{H}$ 
levels. This suggests that the glucose was metabolized solely by glycolysis, and not by the TCA (Diaz-Ruiz et al., 2011). Moreover, $1 \mu \mathrm{M}$ rotenone (complex I inhibitor), which increased the NAD(P)H signal to the point where autofluoresence is likely close to maximal (De Marchi et al., 2014) did not have any effect on the NAD(P)H levels. These effects are consistent with the poor mitochondrial respiration of this cell type. However, the result found that glucose and $\mathrm{KIC}$ increase $\mathrm{NAD}(\mathrm{P}) \mathrm{H}$ in the MIN6 cell lines; an effect consistent with stimulation of mitochondrial electron transport on the oxidative respiration by two substrates (Pralong et al., 1990; Patterson et al., 2000; Luciani et al., 2006; De Marchi et al., 2014; Ghaly et al., 2014).

\section{Conclusion}

Our results suggest that the glycolytic pathway is the predominate pathway for glucose utilization in the 1.1B4 cell and the fate of glucose in MIN6 cells, which are enzymatically similar to $\beta$-cells, is mitochondrial oxidation. Therefore, 1.1B4 cells are not good model to study the bioenergetics of pancreatic beta cells.

\section{References:}

1. Aguilar-Bryan, L. and Bryan, J. (1999) 'Molecular biology of adenosine triphosphate-sensitive potassium channels', Endocr Rev, 20(2), pp. 101-135.

2. Barrett, K.E., Barman, S.M., Boitano, S. and Brooks, H.L. (2012) Ganong's Review of Medical Physiology New York, The McGrawHill Medical.

3. Brown, A.M., Evans, R.D., Black, J. and Ransom, B.R. (2012) 'Schwann cell glycogen selectively supports myelinated axon function', Ann Neurol, 72(3), pp. 406-418.

4. Calhoun, M.W., Thomas, J.W. and Gennis, R.B. (1994) 'The cytochrome oxidase superfamily of redox-driven proton pumps', Trends Biochem Sci, 19(8), pp. 325-330.

5. Chaban, Y., Boekema, E.J. and Dudkina, N.V. (2014) 'Structures of mitochondrial oxidative phosphorylation supercomplexes and mechanisms for their stabilisation', Biochim Biophys Acta, 1837(4), pp. 418-426.

6. Cory, A.H., Owen, T.C., Barltrop, J.A. and Cory, J.G. (1991) 'Use of an aqueous soluble tetrazolium/formazan assay for cell growth assays in culture', Cancer Commun, 3(7), pp. 207-212.

7. Daunt, M., Dale, O. and Smith, P.A. (2006) 'Somatostatin inhibits oxidative respiration in pancreatic beta-cells', Endocrinology, 147(3), pp. 1527-1535. 
8. De Marchi, U., Thevenet, J., Hermant, A., Dioum, E. and Wiederkehr, A. (2014) 'Calcium co-regulates oxidative metabolism and ATP synthase-dependent respiration in pancreatic beta cells', J Biol Chem, 289(13), pp. 9182-9194.

9. Diaz-Ruiz, R., Rigoulet, M. and Devin, A. (2011) 'The Warburg and Crabtree effects: On the origin of cancer cell energy metabolism and of yeast glucose repression', Biochim Biophys Acta, 1807(6), pp. 568576.

10. Doliba, N.M., Qin, W., Najafi, H., Liu, C., Buettger, C.W., Sotiris, J., Collins, H.W., Li, C., Stanley, C.A., Wilson, D.F., Grimsby, J., Sarabu, R., Naji, A. and Matschinsky, F.M. (2012) 'Glucokinase activation repairs defective bioenergetics of islets of Langerhans isolated from type 2 diabetics', Am J Physiol Endocrinol Metab, 302(1), pp. E87E102.

11. Duchen, M.R., Smith, P.A. and Ashcroft, F.M. (1993) 'Substratedependent changes in mitochondrial function, intracellular free calcium concentration and membrane channels in pancreatic betacells', Biochem J, 294 ( Pt 1), pp. 35-42.

12. Gao, Z., Young, R.A., Li, G., Najafi, H., Buettger, C., Sukumvanich, S.S., Wong, R.K., Wolf, B.A. and Matschinsky, F.M. (2003) 'Distinguishing features of leucine and alpha-ketoisocaproate sensing in pancreatic beta-cells', Endocrinology, 144(5), pp. 1949-1957.

13. Ghaly, H., Jörns, A. and Rustenbeck, I. (2014) 'Effect of fluoroquinolones on mitochondrial function in pancreatic beta cells', Eur J Pharm Sci, 52, pp. 206-214.

14. Hirst, J. (2010) 'Towards the molecular mechanism of respiratory complex I', Biochem J, 425(2), pp. 327-339.

15. Hutton, J.C. and Malaisse, W.J. (1980) 'Dynamics of O2 consumption in rat pancreatic islets', Diabetologia, 18(5), pp. 395-405.

16. Ishihara, H., Asano, T., Tsukuda, K., Katagiri, H., Inukai, K., Anai, M., Kikuchi, M., Yazaki, Y., Miyazaki, J.I. and Oka, Y. (1993) 'Pancreatic beta cell line MIN6 exhibits characteristics of glucose metabolism and glucose-stimulated insulin secretion similar to those of normal islets', Diabetologia, 36(11), pp. 1139-1145.

17. Janjic, D. and Wollheim, C.B. (1992) 'Islet cell metabolism is reflected by the MTT (tetrazolium) colorimetric assay', Diabetologia, 35(5), pp. 482-485.

18. Kim, J.A., Wei, Y. and Sowers, J.R. (2008) 'Role of mitochondrial dysfunction in insulin resistance', Circ Res, 102(4), pp. 401-414.

19. Lieber, M., Mazzetta, J., Nelson-Rees, W., Kaplan, M. and Todaro, G. (1975) 'Establishment of a continuous tumor-cell line (panc-1) from a 
human carcinoma of the exocrine pancreas', Int J Cancer, 15(5), pp. 741-747.

20. Lopaschuk, G.D., Ussher, J.R., Folmes, C.D., Jaswal, J.S. and Stanley, W.C. (2010) 'Myocardial fatty acid metabolism in health and disease', Physiol Rev, 90(1), pp. 207-258.

21. Luciani, D.S., Misler, S. and Polonsky, K.S. (2006) 'Ca2+ controls slow NAD $(\mathrm{P}) \mathrm{H}$ oscillations in glucose-stimulated mouse pancreatic islets', J Physiol, 572(Pt 2), pp. 379-392.

22. MacDonald, M.J. and Fahien, L.A. (1990) 'Insulin release in pancreatic islets by a glycolytic and a Krebs cycle intermediate: contrasting patterns of glyceraldehyde phosphate and succinate', Arch Biochem Biophys, 279(1), pp. 104-108.

23. Martens, G.A., Cai, Y., Hinke, S., Stangé, G., Van de Casteele, M. and Pipeleers, D. (2005) 'Glucose suppresses superoxide generation in metabolically responsive pancreatic beta cells', J Biol Chem, 280(21), pp. 20389-20396.

24. Martín, F., Andreu, E., Rovira, J.M., Pertusa, J.A., Raurell, M., Ripoll, C., Sanchez-Andrés, J.V., Montanya, E. and Soria, B. (1999) 'Mechanisms of glucose hypersensitivity in beta-cells from normoglycemic, partially pancreatectomized mice', Diabetes, 48(10), pp. 1954-1961.

25. Matschinsky, F., Liang, Y., Kesavan, P., Wang, L., Froguel, P., Velho, G., Cohen, D., Permutt, M.A., Tanizawa, Y. and Jetton, T.L. (1993) 'Glucokinase as pancreatic beta cell glucose sensor and diabetes gene', J Clin Invest, 92(5), pp. 2092-2098.

26. McCluskey, J.T., Hamid, M., Guo-Parke, H., McClenaghan, N.H., Gomis, R. and Flatt, P.R. (2011) 'Development and functional characterization of insulin-releasing human pancreatic beta cell lines produced by electrofusion', J Biol Chem, 286(25), pp. 21982-21992.

27. Meglasson, M.D. and Matschinsky, F.M. (1984) 'New perspectives on pancreatic islet glucokinase', Am J Physiol, 246(1 Pt 1), pp. E1-13.

28. Meglasson, M.D. and Matschinsky, F.M. (1986) 'Pancreatic islet glucose metabolism and regulation of insulin secretion', Diabetes Metab Rev, 2(3-4), pp. 163-214.

29. Panten, U., Christians, J., von Kriegstein, E., Poser, W. and Hasselblatt, A. (1973) 'Effect of carbohydrates upon fluorescence of reduced pyridine nucleotides from perifused isolated pancreatic islets', Diabetologia, 9(6), pp. 477-482.

30. Panten, U. and Klein, H. (1982) 'O2 consumption by isolated pancreatic islets, as measured in a microincubation system with a Clark-type electrode', Endocrinology, 111(5), pp. 1595-1600. 
31. Patterson, G.H., Knobel, S.M., Arkhammar, P., Thastrup, O. and Piston, D.W. (2000) 'Separation of the glucose-stimulated cytoplasmic and mitochondrial NAD $(\mathrm{P}) \mathrm{H}$ responses in pancreatic islet beta cells', Proc Natl Acad Sci U S A, 97(10), pp. 5203-5207.

32. Pralong, W.F., Bartley, C. and Wollheim, C.B. (1990) 'Single islet beta-cell stimulation by nutrients: relationship between pyridine nucleotides, cytosolic Ca2+ and secretion', EMBO J, 9(1), pp. 53-60.

33. Sakura, H., Ashcroft, S.J., Terauchi, Y., Kadowaki, T. and Ashcroft, F.M. (1998) 'Glucose modulation of ATP-sensitive K-currents in wildtype, homozygous and heterozygous glucokinase knock-out mice', Diabetologia, 41(6), pp. 654-659.

34. Segu, V.B., Li, G. and Metz, S.A. (1998) 'Use of a soluble tetrazolium compound to assay metabolic activation of intact beta cells', Metabolism, 47(7), pp. 824-830.

35. Sekine, N., Cirulli, V., Regazzi, R., Brown, L.J., Gine, E., TamaritRodriguez, J., Girotti, M., Marie, S., MacDonald, M.J. and Wollheim, C.B. (1994) 'Low lactate dehydrogenase and high mitochondrial glycerol phosphate dehydrogenase in pancreatic beta-cells. Potential role in nutrient sensing', J Biol Chem, 269(7), pp. 4895-4902.

36. Sener, A. and Malaisse, W.J. (1976) 'Measurement of lactic acid in nanomolar amounts. Reliability of such a method as an index of glycolysis in pancreatic islets', Biochem Med, 15(1), pp. 34-41.

37. Skelin, M., Rupnik, M. and Cencic, A. (2010) 'Pancreatic beta cell lines and their applications in diabetes mellitus research', ALTEX, 27(2), pp. 105-113.

38. Soria, B., Tudurí, E., González, A., Hmadcha, A., Martin, F., Nadal, A. and Quesada, I. (2010) 'Pancreatic islet cells: a model for calciumdependent peptide release', HFSP J, 4(2), pp. 52-60.

39. Valdez, L.B., Zaobornyj, T. and Boveris, A. (2006) 'Mitochondrial metabolic states and membrane potential modulate mtNOS activity', Biochim Biophys Acta, 1757(3), pp. 166-172.

40. WARBURG, O. (1956) 'On the origin of cancer cells', Science, 123(3191), pp. 309-314.

41. Wright, S.H. (2004) 'Generation of resting membrane potential', $A d v$ Physiol Educ, 28(1-4), pp. 139-142. 